DOE Technical Report No. DOE/PC/88921-13

Thirteenth Quarterly Report on Research Grant No. DE-FG22-88PC88921

Title: SPIN MAPPING OF COAL STRUCTURES WITH ESE AND ENDOR

Principal Ynvestigators: R. L. Belford and R. B. Clarkson

Institution: University of Illinois at Urbana-Champaign

Date: December 1, 1991

US/DOE Patent Clearance is not requiriad prior to publication of this document.

$\mathrm{DOE} / \mathrm{FC} / 88921-13$

DE92 01.5513

\title{
ABSTRACT
}

10.

Advanced electron paramagnetic resonance (EPR) techniques - ENDOR, ESE, and VHF-EPR - are used to probe the molecular structure and surface properties of coals. During a probe of the surface response of coal particles to oxygen, we have also made synthetic chars for comparison. This quarter's report concerns preparation and characterization of these chars. This work will be published.

\section{OBJECTIVES and APPROACH}

The goals of this program include developing a system for the analysis of the chemical forms of organic sulfur in coal and for study of coal particle surfaces by multifrequency EPR spectroscopy, ENDOR, and ESE spectroscopy and applying it to coals, to the effects of treatment upon their sulfurcontaining organic components, and to related carbonaceous materials (chars and the like). The approach is to utilize the naturally-occurring unpaired electrons in the organic structures of coals as spies to provide molecular structure information, reading out the information with Electron Paramagnetic Resonance (EPR) spectroscopy. Several forms of EPR are employed: Multifrequency contiunuous-wave (CW) EPR, from $1 \mathrm{GH}<$ to $240 \mathrm{GHz}$ source frequency; electron-nuclear double resonance (ENDOR), in which NMR spectra at paramagnetic centers are obtained by EPR detection; and pulsed EPR, including ESE (Electron Spin Echo) spectroscopy.

\section{REPORT: EXPERIMENTAL; RESULTS; CONCLUSIONS AND RECOMMENDATIONS}

Preface: Carbonization results from the heating of a carbonaceous material in an inert atmosphere. This process encourages the evolution of non-carbon elements as gaseous products and tar and the formation of a semipo:ous solid carbon product. During thermal decomposition, solid graphite-like sheets of aromatic carbon are formed, arising from free radical intermediates, some of which remain in the product carbon[1,2]. Activation processes can increase the porous structure of the product by revealing interstices which would have been obstructed by tar in an non-active carbon. 'The primary function of the chemical activating agent is one of dehydration, influencing the course of carbonization by reducing the production of volatile by-products and tar, increasing carbon yield and porosity[3]. A second function has been reported by Marsh[4]: potassium and other alkali salts appear to encourage pore formation by catalyzing extensive crosslinking between growing carbon chains formed as carbonization intermediates.

Laboratory preparation of active carbon from carbonaceous materials can proceed in two different manners[3]. The first, physical activation, occurs in two steps: an initial carbonization process where the carbonaceous material is heated in an inert atmosphere which is followed by a

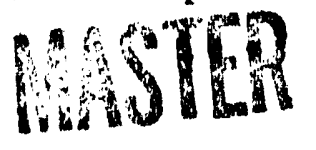


second activation process where the carbonized material is reheated in the presence of a gaseous agent such as carbon dioxide, steam or oxygen. This encourages the formation of a complex porous structure by burning away more reactive portions of the carbon skeleton. External heating to temperatures between $800^{\circ}-1100^{\circ} \mathrm{C}$ is required to drive the carbon-gas reaction. Alternately, a one step chemical activation can be performed where the carbonaceous precursor is mixed with an activating agent $\left(\mathrm{KOH}_{3} \mathrm{ZnCl}_{2}, \mathrm{H}_{3} \mathrm{PO}_{4}\right)$ which restricts the formation of tar-like products that can block newly formed pores. Since activation is concurrent with carbonization, the final heat treatment temperature (HTT) can be lower than that which is required by physical activation.

Previous Electron Paramagnetic Resonance (EPR) characterization of carbons produced from sugars and other carbonaceous materials have provided several areas for additional inquiry which have been pursued. Many reports have described the influence of paramagnetic gasses $\left(\mathrm{O}_{2}\right.$ as well as NO) on the linewidths of these substances $[5,6,7,8]$. In all cases, the immediate effect was reversible over a broad range of pressures. However, the magnitude of the effect has been seen to diminish over a period of time if the samples are continuously exposed to atmospheric oxygen[9]. Examination of carbons derived from sucrose has shown a correlation between electronic character and HTT[10]. Specifically, the concentration of conduction band electrons increases with increasing HTT, after a maximum free radical concentration is reached at $600^{\circ} \mathrm{C}$. This factor influences the choice of HTT for the selected carbons.

The purpose of this work is to study the effects of the active carbon preparation procedure on the oxygen response of the EPR linewidth. This is accomplished by 1) the utilization of different chemical activating agents during carbonization, 2) modification of the amount of activating agent present during carbonization, 3) characterization of the BET surface area and pore volume distribution with nitrogen adsorption analysis, and 4) observation of the EPR line of selected carbons.

\section{Experimental:}

Carbon preparation - Since the sharpest resonance signal is produced by carbons with HTT in the region of $600^{\circ} \mathrm{C}$, chemical activation was selected as the method for further study. The carbons were prepared from Fisher Chemical reagent grade sucrose, using Fisher Chemical reagent grade potassium hydroxide and zinc chloride as activating agents. Traditionally, zinc chloride activation is performed by saturating a cellulose material with a concentrated solution of the salt[11]; however, sucrose was solected as a starting material to give reproducible results between individual carbons. Sucrose and an activatung agent were combined in varying ratios by mass and ground with: a mortar and pestle to homogeneity. The activating agent/sucrose mixture was transferred to a ceramic boat in a horizontal tube furnace fitted with a stainiess steel insert connected to a length of copper tubing and a gas bubbler containing a dilute $\mathrm{ZnCl}_{2}$ solution. Under a constant flow of argon gas ( $2.5 \mathrm{SCFH}$ ), the sample was heated according to programmed temperature control at a rate of $10^{\circ} \mathrm{C} / \mathrm{hr}$ to a HTT of $620^{\circ} \mathrm{C}$. The carbon remained at the HTT for a minimum of 12 hours before cooling to room temperature. Following heating, the carbon was transferred to a glove bag flushed with nitrogen gas for manipulation. The carbon was ground as a slurry with deionized water and vacuum filtered through a fritted funnel. An additional $500 \mathrm{~mL}$ of deionized water was used to remove any residual activating agent. Dried carbons were stored under nitrogen in the bag. Table I lists the carbons selected for discussion.

Adsorption analysis - Surface characteristics were determined utilizing a Micromeretics ASA.P 2400 adsorption analyzer. Prior to analysis, all samples were degassed for 24 hours at $120^{\circ} \mathrm{C}$. Full adsorption and desorption isotherms were obtained for each carbon using nitrogen at $77 \mathrm{~K}$ as the adsorbent. The BET surface area was calculated from relative pressures $\left(P / P_{\curvearrowright}\right)$ between 0.001 and 0.25 on the adsorption isotherm, using $0.162 \mathrm{~nm}^{2}$ as the cross-sectional area of the nitrogen molecule. Pore volume distributions were calculated from the adsorption isotherm using the BJH technique[12]. 
TABLE 1. Preparation conditions for sucrose active carbons

\begin{tabular}{cccc}
\hline Carbon & Activating agent & $\begin{array}{c}\text { Ratio of activating agent to } \\
\text { sucrose } \\
\text { (8 agent:g sucrose) }\end{array}$ & $\begin{array}{c}\text { BET } \\
\text { Surface Area } \\
\left(\mathrm{m}^{2} / \mathrm{g}\right)\end{array}$ \\
\hline 1 & $\mathrm{none}$ & $2: 1$ & not obtained \\
2 & $\mathrm{ZnCl}$ & $2: 1$ & 1171 \\
3 & $\mathrm{KOH}$ & $2: 1$ & 433 \\
4 & $\mathrm{ZnCl}_{2}$ & $1: 1$ & 1100 \\
5 & $\mathrm{ZnCl}_{2}$ & $1: 2$ & 1138 \\
6 & $\mathrm{ZnCl}_{2}$ & $1: 3$ & 1055 \\
7 & $\mathrm{ZnCl}_{2}$ & $1: 4$ & 672 \\
8 & $\mathrm{ZnCl}_{2}$ & -1.5 & 670 \\
9 & none & & 156 \\
10 & $\mathrm{ZnCl}_{2}$ & & 906 \\
\hline
\end{tabular}

Electron paramagnetic resonance spectroscopy - EPR analysis of the resonance linewidth of the carbons in the presence of differing pressures of oxygen was performed on a Varian E-L.ine spectrometer with computerized data acquisition. The microwave power was $2 \mathrm{~mW}$ and $100 \mathrm{kHz}$ field modulation was used. Powder samples were removed from nitrogen storage and connected to a vacuum manifold for the duration of the experiment. The oxygen source for the experiments was stored in a two liter bulb attached to the manifold in which $760 \mathrm{~mm} \mathrm{Hg}$ of oxygen (Matheson, extra dry grade) had been introduced. The pressure of oxygen admitted into the sample, $\mathbf{P}_{\mathrm{o} 2}$, was measured with a Leybold-Heraeus Divac-N barometric gauge. Since information from kinetic studies showed a rapid equilibration time for the samples upon exposure to oxygen (on the order of seconds), the carbons were evacuated for an hour prior to analysis and spectra were taken ten minutes after the admission of oxygen into the sample, allowing sufficient time for equilibration between solid and gas. Spectral analysis of the single resonance linewidth, $\Delta \mathrm{B}_{p}$, was performed with several utility programs: EPRWare, courtesy of Scientific Software Services and DATAEG and PEAKS written by members of the Illinois EPR Research Center. Linewidths obtained from two component spectra were assumed to be that of the broad, variable component.

Results and Discussion:

The EFR resonance line - The cartons selected for study give a single resonance line at approximately $g=2.00$ which displays a completely reversible dependency of $\Delta B_{p p}$ on the partial pressure of paramagnetic gas in contact with the carbon. Thus, the linewidth is modulated by $\mathrm{O}_{2}$ and $\mathrm{NO}$, but not by nonparamagnetic gases such as $\mathrm{Cl}_{2}$ or $\mathrm{CO}_{2}$.

Studies performed on carbon \#1 demonstrate an interparticle interaction that can be prevented by separation of the carbon particles with an inert solid dilutant such as potassium bromide. Studies performed on different dispersion mediums have shown $\mathrm{KBr}$ to be a suitable dispersant[14]. The lineshapes of carbon \#1 as a neat sample and as a dispersion of one part carbon to 100 parts $\mathrm{KBr}$ by mass were compared. Reducing the interaction between particles reduces the Lorentzian character of the resonance line, resulting in a more Gaussian shape. This phenomenon has been described previously and is attributed to the electric properties of materials with low resistivities[10]. The EPR properties of a such materials experience problems, such as lineshape changes, when the particle size 
of the sample under study is larger than the microwave skin depth. Dilution and additional micronization overcome difficulties associated with skin depth. The resulting linewidth dependency for the diluted sample illustrated in Fig. 4 differs from the neat sample in its increased linearity and decreased $\mathrm{d}\left(\Delta \mathrm{B}_{\mathrm{pp}}\right) / \mathrm{dP}_{\mathrm{O}_{2}}$. It is possible that the effect of adsorbed paramagnetic gases is partially dependent on particle contact, as evidenced by the decreased influence of oxygen over unpaired spins in the diluted sample. Since the dilutant decreased the kinetics of equilibrium by more than a factor of one hundred, small quantities of the selected samples were studied neat.

An additional factor involved in the analysis of the lineshape is the presence of a two-component line. This type of EPR line consists of two overlapping single resonances arising from two distinct sites in the carbons and was observed in several of the carbons selected for study, but could not be correlated to any parameters associated with carbon preparation. The narrow component arises from a part of the sample that is not interacting with oxygen, while the broad component represents the portion of the sample under oxygen influence. A constant narrow component unaffected by the changing pressures of oxygen, while the broader component changes with the introduction of the paramagnetic gas. This effect may arise from reduced oxygen access to portions of the carbon particles under study. This effect was decreased only slightly by additional grinding of the sample with a mortar and pestle. For the purposes of linewidth analysis, the fixed narrow component was neglected and $\Delta \mathrm{B}_{\mathrm{pp}}$ was obtained from the broader, variable resonance.

Storage cunditions and the effect of different activating agents - Investigators have demonstrated that non-active carbons left in atmosphere for extended periods of time show decreases in the linewidth dependericy[9]. This has been attributed to the permanent formation of peroxyl radicals, R-O-O, with the free radicals trapped in the aromatic lattice of the carbons. Extensive studies were performed on carbon $\# 2$ over an eight month period. The bulk of the material was stored under nitrogen, while a sample was stored in atmosphere to examine the influence of atmospheric oxygen on the linewidth dependency of an active carbon. The linear dependency does not change as a function of time within a degree of experimental error. Ingram reported the total loss of dependency after a period of six months, an effect which was not seen in the active carbons selected for study.

Different chemical agents present during carbonization can influence the composition of the final product through dissimilar mechanisms to yield carbons with various characteristics $[4,15]$, a fact substantiated by the adsorption data discussed above. Figure 9 shows the linewidth dependency of carbons activated by two chemical agents, zinc chloride and potassium hydroxide. The $\mathrm{ZnCl}_{2}$ activated carbon displays a high degree of linearity and a moderate response over a broad range of oxygen pressures, while the $\mathrm{KOH}$ activated carbon displays linearity over a narrower range but a high response. This difference seems to result from the difference in microporosity between the two carbons. When the EPR dependencies are correlated with the adsorption pore volume distributions for carbons \#2 and \#3, a noticeable trend is apparent. A high degree of microporosity yields a carbon with a linear clependency, while increasing nonlinear dependency behavior is displayed as mesoporous character increases. These factors which influence the nitrogen adsorption isotherm translate to the oxygen dependency measured by EPR. Thus, when exploring chemical activating agents, the degree of microporosity must be considered as it applies to the EPR properties of the carbon.

$\mathrm{ZnCl}_{2}$ was selected as the activating agent for additional consideration due to its linearity over a broad range of oxygen pressures useful for a variety of oximetry applications.

Surface area effects on the oxygen response - A series of carbons were produced with varying ratios of $\mathrm{ZnCl}_{2}$ to sucrose and linewidth dependencies on oxygen pressure measured. These dependencies follow a general trend of decreasing linearity and response as the amount of chemical agent present during carbonization is decreased. This trend can be attributed to a combination of two factors. First, the decreasing linearity is correlated to the increasing mesoporous character of the carbons as 
the ratio of activating agent to sucrose is reduced. Thus, non-linearity displayed by carbon $\# 6$, a $\mathrm{ZnCl}_{2}$ activated carbon, correlates to its mesoporous character in a manner similar to that of carbon \#3 as discussed above. Second, the decreasing response can be seen as a function of BET surface area. Responses were calculated from the slope of a line fitted to the linear region of the dependence data. Increasing the BET surface area of the carbon increases the response to oxygen. This effect could be explained by increased oxygen access to the unpaired spins created during carbonization. Interaction between the oxygen and the radical site would become greater as the distance between the two species decreased, a factor which occurs as the surface area increases. Additionally, a greater surface area can enhance the number of oxygen molecules interacting with the surface radical sites, resulting in an increased response.

Conclusions: The characterization of the selected carbons has demonstrated several important features of chemically activated sucrose carbons which are scientifically interesting and also make them ideal choices for oximeters[16]. (1) The surface characteristics are easily manipulated by alterations in the preparation procedure. (2) These alterations are reflected in the oxygen response of the EPR linewidth of the carbons. The oxygen dependence is linear and the degree of linearity is dependent on the pore volume distribution. (3) The response is stable to atmospheric oxygen effects, unlike non-activated carbon.

\title{
References:
}

1. E. Fitzer, K. Mueller and W. Schaefer, In Chemistry and Physics of Carbon (Edited by P. L. Walker, Jr.), Vol. 7, p. 237. Marcel Dekker, New York (1971).

2. I. C. Lewis and L. S. Singer, In Chemistry and Physics of Carbon (Edited by P. A. Thrower and

P. L. Walker, Jr.), Vol 17, p. 1. Marcel Dekker, New York (1981).

3. R. C. Bansal, J. B. Donnet and F. Stoeckli, Active Carbon, Marcel Dekker, New York (1988).

4. H. Marsh and P. Walker, Fuel Proc. Tech. 2, 61 (1979).

5. A. D. Grishina and A. P. Semenov, Electrokhimya 9, 719 (1973).

6. K. Antonowicz, Carbon 1, 111 (1964).

7. R. C. Pastor and R. H. Hoskins, J. Chem. Phys. 32, 264 (1960).

8. J. W. Armstrong, C. Jackson and H. Marsh, Carbon 2, 239 (1964).

9. D. J. E. Ingram, Proceedings of 3d Biennial Carbon Conf., p. 93. Pergamon, New York (1957).

10. L. S. Singer, Proceedings of 5th Carbon Conference, p. 37. Pergamon Press, New York (1961). 11. M. Smisek and S. Cerny, Active Carbon: Manufacture, Properties and Applications, Elsevier, Amsterdam (1970).

12. E. P. Barrett, L. G. Joyner and P. P. Halenda, J. Amer. Chem. Soc. 73, 373 (1951).

13. F. Rodriguiez-Reinoso, In Carbon and Coal Gasification (Edited by J. L. Figueriedo and J. A. Moulijin), p. 601. Martinus Nijhoff, The Netherland (1986).

14. H. L. Retcofsky, M. R. Hough, M. A. Maguire, and R. B. Clarkson, In Advances in Chemistry Series (Edited by Martin L. Gorbaty "d K. Ouchi), Vol 192, p. 39. (1981).

15. W. K. Tang W. K. Neil, J. Polym. Sci.: Part C 6, 65 (1964).

16. H. M. Swartz, S. J. Boyer, P. Gast, J. F. Glockner, H. Hu, K. Liu, M. Moussavi, S.W. Norby, N. Vahidi, T. Walczak, M. Wu and R. B. Clarkson, Magn. Reson. Med. 20, 333 (1991).

\section{DISCLAIMER}

\begin{abstract}
This report was prepared as an account of work sponsored by an agency of the United States Government. Neither the United States Government nor any agency thereof, nor any of their employees, makes any warranty, express or implied, or assumes any legal liability or responsibility for the accuracy, completeness, or usefulness of any information, apparatus, product, or process disclosed, or represents that its use would not infringe privately owned rights. Reference herein to any specific commercial product, process, or service by trade name, trademark, inanufacturer, or otherwise does not necessarily constitute or imply its endorsement, recommendation, or favoring by the United States Government or any agency thereof. The views and opinions of authors expressed herein do not necessarily state or reflect those of the United States Government or any agency thereof.
\end{abstract}


DATE

FILMED

8127192 
